This PDF is a selection from an out-of-print volume from the National Bureau of Economic Research

Volume Title: The Rate and Direction of Inventive Activity: Economic and Social Factors

Volume Author/Editor: Universities-National Bureau Committee for Economic Research, Committee on Economic Growth of the Social Science Research Council

Volume Publisher: Princeton University Press

Volume ISBN: 0-87014-304-2

Volume URL: http://www.nber.org/books/univ62-1

Publication Date: 1962

Chapter Title: Inventive Activity: Problems of Definition and Measurement Chapter Author: Simon Kuznets

Chapter URL: http://www.nber.org/chapters/c2112

Chapter pages in book: (p. 19 - 52) 


\title{
Inventive Activity : Problems of Definition and Measurement
}

\author{
SIMON KUZNETS \\ HARVARD UNIVERSITY \\ Problems of Definition
}

INVENTIVE activity is limited in the following discussion to action concerned with technical inventions, yielding new products to be turned out and new devices to be used in economic production. We thus exclude social inventions, new methods of inducing human beings to compete and cooperate in the social progress-ranging from systems of pay and incentives or arrangements of work sequence within a firm to such far-reaching legal inventions as the modern corporation or the planning system of an authoritarian economy. The effects of social inventions on economic productivity are obviously major and profound, but the occupational groups connected with social inventions and the institutional arrangements for their production, selection, and application are so different from those involved with technical inventions that the two can hardly be treated together. And it need scarcely be mentioned that we also exclude creative work of an esthetic character, in which economic use is not the major aim or test.

Of the several characteristics usually formulated in defining technical inventions, the first discussed here is that an invention is a new combination of available knowledge concerning properties of the material universe. Two questions immediately arise. First, must the combination be new ? Second, must it be of already known properties and processes without containing new discoveries?

The requirement of newness serves, presumably, to eliminate duplication in measuring the output of inventive activity, for clearly two inventions identical in character do not represent two distinct additions to the stock of technological knowledge. But if we are concerned with the input of inventive activity, if two identical inventions have been made independently of each other, and if we measure the productive factor involved by the capacity to produce inventions, then these two inventions signify a greater input of inventive activity and hence, all other conditions being equal, a greater supply of inventive

Nore: I am indebted to Jacob Schmookler for helpful comments on an earlier version of this paper. 
capacity than one invention. Furthermore, the supply of inventive capacity involved is not necessarily smaller than that represented by two independent and different inventions. It follows that an interest in the input of inventive capacity and a technological measure of inventive activity would require that an invention be defined as an independently derived rather than a new device; whereas an interest in the output of inventive activity as a contribution to technological knowledge would require that an invention be a new device, in the sense of constituting a real addition to the stock of available knowledge. Paradoxically, this may mean that a "borrowed" (to use a polite adjective) invention may be new, and an independent invention may be unborn if it has not yet become widely known. Inventions as a measure of input of inventive activity may thus differ from inventions as a measure of additions to the stock of knowledge both because of duplication of independent inventions and because of what might be called unknown or still-born cases.

The requirement that an invention be a combination of available and existing knowledge concerning properties of the material universe, with the implicit distinction between invention and discovery, has been criticized-partly because of the difficulty of drawing the distinction. More importantly, in that contrast, discovery is viewed as a process of unveiling something already existing, implying an indefensible theory of scientific knowledge. To be sure, much scientific work is devoted to discovering testable properties of the physical universe-assembling valuable information on coast lines, melting and boiling points, and so on. And yet it must be recognized that scientists in "discovering" their theories are in fact "inventing" them-for clearly the order which they bring into the structure of the universe is of their own contriving even though the test lies in an agreement between theoretical conclusions and observational data mirroring the real world. We may also admit that some scientific discoveries permit easy application without further invention and that many inventions involve, or quickly bring about, discovery of additional properties of the material universe; hence the distinction between these areas is far from sharp. Nor do we, in this analysis, have to accept patentability as the basis of the distinction, although it does reflect significant differences between technical inventions and scientific discovery.

Despite these difficulties it seems to me that the distinction should be retained for several important reasons. First, no problem of practicality or usefulness arises in scientific discovery. Any scientific finding 
-whether it is specific information about the atomic weight of some organic compound or a wide-flung theory of nuclear structure, whether it is an accurate description of the coast line of the Persian Gulf or the most speculative theory of geological formation-is potentially useful, since any addition to our tested knowledge of the material universe is exploitable in economic production (the latter being a reshuffling of the material universe to make it better serve human purposes). Second, most scientific discoveries are immediately useless - certainly so far as the scientist is concerned, for he is not attempting the application of the results to useful ends even if he is aware of them, which often he is not. Third, the occupational groups, the institutional arrangements, and the individual motivations of inventors are quite different from those of scientists. Finally, since scientific discovery is usually general in character, each discovery provides a base for a wide variety of potential practical uses-technical inventions among them (the main reason for nonpatentability). At least since the second half of the nineteenth century, there have been many more scientific discoveries than inventions that could have been based upon them, and the lags between scientific discoveries and consequent inventions have been numerous. Conversely, there have been many inventions based on properties of the material universe, the knowledge of which has not been fully incorporated into the corpus of scientific theory. These lags and leads are indications that the two types of addition to knowledge have distinctly different properties. For more effective organization of the field of inquiry and sharper focusing of research, it would seem to me better to keep the line of distinction and restrict the definition of technical inventions to new combinations of existing knowledge designed for practical use in production-even at the danger of overlooking the contribution to knowledge that much inventive activity may supply.

A second characteristic claimed for a technical invention is that it must be the product of a mental effort above the average-although we do not insist on a flash of genius or any other presumably rare manifestation of man the contriver. The aim here is to distinguish between inventions and the host of improvements in technique that are made in the daily process of production and are the result of lowlevel and rather obvious attentiveness or know-how. Not that the cumulative effect of such obvious improvements on economic productivity is slight. It is merely that an invention is supposed to be of 
some minimum magnitude - magnitude not of economic impact but of input of some uncommon mental capacity of human beings.

Disregarding for the present the importance of this characteristic in connection with patent legislation or any other system of rewards, we may ask why the distinction between inventions and improvements is attempted. If we could measure the economic magnitude of each item from the most obvious improvement to the most major invention, would we still be interested in the distinction? The answer is "yes," if we assume that the upper segment of this range, i.e., the inventions which in fact provide the basis for the improvements, can only be produced by people with unusual equipment, and hence distinguishing them would lead to a more fruitful examination of the type of effort and corresponding type of personality involved. In particular, the distinction suggests that while inventions and improvements may be graded by their economic magnitude, no such continuity exists in the range of human ability involved; that there are qualitative differences between the effort and capacity associated with inventions and those associated with obvious improvements, so that no shift from the one to the other can be attained, no matter how much training, education, or other use of reproducible resources is thrown into the scale. The characteristic thus emphasizes the input side of inventive activity and implies that the distinctive factor can be identified and studied.

Whether this is a valid assumption, whether an effective line can be drawn between the capacity to produce inventions and that to make obvious improvements, and whether the particular type of ability connected with the former can be identified and studied, are questions best left to other papers in the conference. But it clearly affects the problem of measurement, and we shall return to it in the next section.

A third characteristic of a technical invention that may be suggested is that it be useful, i.e., that it be a practicable device which, when employed, would either reduce the cost of producing already established goods or make possible the production of new goods for which the demand is sufficient to cover costs. The reason for suggesting this characteristic is obvious enough, particularly to economists: we are interested in inventions because and insofar as they contribute to the growth of economic production. Yet one can easily envisage inventions that do not. For example, a new device for producing hairpins which is more costly - now and in the foreseeable future-than the presently used devices, is not useful in the sense in which we employ this term.

The difficulty with this criterion - and it has not been used in patent 
practice for some time-is that it requires knowledge concerning the economic effects of an invention after it has gone through a period of adaptation in pilot operation, and after an attempt has been made to apply it on an adequate scale to test its market potentialities. Many inventions never reach this stage; and practically all inventions when they are completed and even when they are recorded, are still far from the test of usefulness. To be sure, a patented invention must "work," i.e., the device must perform the task that the inventor claims for it; and the same test must be applied when unpatented inventions are recorded. But technical feasibility is a far cry from economic usefulness; and no assurance of the latter can be given at the time the invention is made. We must, therefore, shift the formulation to potential usefulness, although the question then arises as to whose judgment is to be accepted. The least demanding criterion would rely on the judgment of the inventor himself or of the firm under whose auspices he may be working. This standard does not provide a very firm base for identifying usefulness; but it at least permits an inclusive definition of inventions, on the assumption that they would not be made unless each inventor believed that his device was potentially useful in economic production.

But is this assumption valid? Are inventions made with this criterion clearly in mind? Or are many of them made out of sheer love of tinkering, pride of authorship, or instinct of contrivance without any regard to their potential usefulness in economic production? If the latter were the case there would be a vast disparity between the input of inventive activity and the output of potentially useful inventions, for there would be a vast number of inventions not designed for economic production. The disparity is large enough when we accept as the test of potential usefulness the judgment of the inventor or his firm; it would be enormous indeed if a great deal of inventive activity were not economically oriented. One may ask whether we should perhaps completely disregard the criterion of even potential usefulness and define an invention as any new device, employable in economic production, that represents some minimum mental effort. Yet, even if we did so, we would still have to make some assumptions as to the bearing of inventions on decreasing costs or on creating new products in the economy. Moreover, if we disregarded the criterion of usefulness we would be in fact removing an important part of invention as activity and as input. For it may be of the essence of invention that the search is not merely for a new device-which may be relatively easy- 
but for a device that is more economical or attractively novel than existing ones. This is the major difficulty involved in inventing, the very aspect that may require that minimum effort discussed as the second characteristic. And while some inventive activity may be mere tinkering, and the potential usefulness of many inventions may be exaggerated, I would strongly urge that the criterion of usefulness be retained as a constituent characteristic in the definition of a technical invention; that a distinction be made at least implicitly between economically oriented inventive activity and noneconomically oriented tinkering; and that some attention be devoted to the different levels of judgment of potential usefulness in the analysis of both inventive activity and inventions. For this whole matter of usefulness has, to my view, obvious bearing upon a variety of questions concerned with measurement.

\section{The Magnitude of an Invention}

The preceding section led to a definition of inventive activity as being concerned with technical inventions, i.e. new combinations of existing knowledge in devices potentially useful in economic production and resulting from a mental performance above the average. The difficulties in measuring an activity so defined are perhaps obvious enough; but before we review the available indexes, it may be well to discuss explicitly the problems of measurement by dealing with the magnitude of a single invention.

It follows from the earlier comments that an invention has a technical and an economic side; and, of course, it has a past and a future. The combination of these two sets of aspects gives us four views of the magnitude of an invention: (1) the technical problem overcomea view of the technical past; (2) the technical potential, i.e. the effect of the invention on further technical changes and the progress of technology in general-a view of the technical future; (3) the economic cost, i.e. the resources consumed or foregone in the "production" of the invention - a view of the economic past; and (4) the economic potential, i.e. the contribution of the invention to cost reduction or to the production of new goods in the economy-a view of the economic future. If we could set down meaningful figures for each invention under each of the four heads, the problem of measuring the input and output of inventive activity would be almost entirely removed, for any remaining difficulty of identifying inventions could be minimized. As an economist I would be willing to settle for meaningful quantities 
under (3) and (4). But knowing that no easy answers are available, I feel compelled to retain (1) and (2), for whatever help the examination of the technical problems and potentials of an invention may give us in considering its economic cost and contribution.

1. Consideration of the technical problem solved by an invention brings us right back to invention as the product of human performance of more than average quality. The difficulty is obviously related to the existing stock of knowledge; and it is assumed that such knowledge is accessible and that its possession is a necessary but not, in itself, sufficient condition of an invention. Given the search for an economically useful device as part of the task, the other condition is the ability to use the knowledge in some new and effective combination.

While a mere economist must tread warily here, it does seem to me that the magnitudes of the technical difficulties resolved by various inventions differ and, in that sense, different inventions represent different magnitudes of inventive capacity and of its input. To illustrate: Kay's flying shuttle, a useful modification in the handloom, represented the solution of a lesser technical problem than Arkwright's water-frame which mechanized spinning; Watt's separate condenser solved a greater technical problem than the earlier improvements in Newcomen's engine; and to use a modern example, the invention of an effective engine using nuclear power for air travel would represent the solution of a greater technical problem than the invention of another and better mechanical pen.

These are of course selected examples; a comparison of the technical problems resolved by Watt's inventions relating to the steam engine and Faraday's and his successors' on the electric generator would not yield unequivocal answers. All I am arguing is that above the threshold where obvious improvements cease and inventions begin the magnitudes of the technical problems resolved by inventions differ widely. Some of the problems are difficult and major because they are concerned with harnessing a new and previously intractable source of power; others, because they involve the conversion of a vast, complex, and time-consuming set of hand operations to machine operation; still others, because they are concerned with the displacement of a widely used but exhaustible material by a new one whose qualities, other than a suitability for various purposes, are still not well known. By contrast, the technical problems in other inventions seem to be of smaller magnitude, because they are modifications within the existing framework of technology and do not involve such new "large" 
elements as power, materials, or a complex set of manual operations.

Granted such differences between major and minor technical problems, I would argue next that the resulting major and minor inventions represent different levels of inventive activity. The only other explanation would be the gradualist and additive theory of inventions in which a major invention is the result of the long cumulative addition of small increments with the final inventor getting the credit; a minor invention is the sum of a shorter cumulative series. Inventions and inventors do, of course, depend upon the cumulation of knowledge - scientific discovery, past invention and improvements, and the state of the artsbut this dependence does not deny the proposition that specific inventive capacities vary, with the corollary that the difference between major and minor technical difficulties resolved by invention often represents different degrees of ability on the part of inventors. But as indicated in my earlier comments, I claim no knowledge of this subject which is quite fundamental in the whole problem of the supply of inventive capacity. It will, I hope, be dealt with by others. For the present I shall assume that the magnitude of an invention as represented by the technical problem resolved is correlated with the capacity of the inventive activity responsible.

2. Some inventions, representing as they do a breakthrough in a major field, have a wide technical potential in the sense that they provide a base for numerous subsequent technical changes. In this respect the invention of the first steam engine, which initiated a whole series of major technical changes and applications - what might be called subsidiary inventions-is vastly different from the invention of the safety match or the pocket lighter. This wide range is for our purposes the major characteristic relevant to the problem of measurement.

There is some positive correlation between the magnitude of the technical problem resolved by an invention and the magnitude of its technical potential. If an invention introduces a new industrial material of potentially wide use, or harnesses a new source of power, or mechanizes a wide variety of previously labor consuming operations, the very magnitude of the problem may mean that the first and pioneering invention has not overcome the difficulty fully, that much remains to be done by future inventions, and that the technical potential thus opened up is wide. But this association cannot be fully relied upon. A highly ingenious new device which overcomes a difficult technical problem may not provide a base for many further technical changes; while another invention that does not require comparable ingenuity 
in overcoming a difficult technical problem may become a base for major subsequent changes in the technique of the process. I may be wrong in thinking that the Bessemer converter, measured by the magnitude of the technical problem resolved, was a "greater" invention than the open-hearth furnace; yet it was the latter and not the former that became the basis of modern steel technology, a foundation upon which a long series of technical improvements and changes has been built.

3. The economic cost of an invention can presumably be measured by the value of the resources used in producing it - the time of the inventor and his collaborators and the materials consumed, valued in terms of alternative uses or market prices.

Three questions are immediately suggested by this formulation. First, if $n$ inventors are working on invention $X$ and one is successful, we should presumably include the resources used by all $n$ inventors, not just by the one successful. This creates no problem if the cost of a stream of inventions over a long period is to be measured since we could presumably use the input of all would-be inventors, successful and otherwise. But the specification of the cost of any single invention, or of a limited group of them, calls for the capacity to identify all the inventor inputs directed toward its attainment.

Second, how far back in the line of causation should we go in considering the cost? Should we include in the cost of an invention the resources devoted to securing the knowledge, via scientific research and discovery, that underlies it? Even if theoretically desirable, it would be impossible to specify fully the antecedent knowledge embodied in a given invention. But more important, if we treat inventive activity like other production activity, there is no more reason to charge it with the costs of scientific and other knowledge (except as it is already reflected in the value of a trained inventor's time) than there is to charge the production of any commodity - which is also based on a wide stock of antecedent knowledge-with such costs.

Third, there is the problem of specifying the completion of an invention and determining how far forward the cost calculation should be carried. If we adhere to the definition followed here, an invention is completed when it is shown to "work" and when a claim of possible economic usefulness is made for it. Substantiation of this claim might require a prolonged period of trial use and adaptation, a pilot operation, and sufficient mass application to permit most of the improvements that make for economical production. The economic cost of a 
tested invention may, therefore, be a large multiple of the cost of an untested invention; and it is important to distinguish between the two. Since many inventions are never fully applied and tested, it is only the economic cost of untested inventions that can be calculated for the whole universe of inventions; and it is the economic cost of untested inventions that corresponds to our definition of inventive activity. But it is useful to keep in mind the additional development costs involved in those inventions selected for application and service as innovations in productive activity.

4. The gross economic value of an invention to the inventor or the private user is either the capital sum received for it or the capitalized value of the returns that may be assigned to it. Such assignment and capitalization may call for complicated and imprecise procedures, but we are more concerned here with the economic contribution to society. ${ }^{1}$

If an invention involves an increase in productivity in turning out established goods, the gross magnitude of its economic contribution to society is the discounted value of the additional yield that it will permit. Given the data on such additional yield, its proper evaluation requires, however, either knowledge of or assumptions concerning the price elasticites of demand and supply. ${ }^{2}$ If an invention involves a new product, a rough approximation to its economic magnitude seems to me to be possible only if the new product can be treated as a substitute for an old so that it again becomes feasible to estimate the additional yield and seek for a defensible economic basis for evaluating it.

Granted the difficulties of the type of approximation just noted, two further observations can be made. First, the estimate involves a forecast, the weight of which is greater the longer the future of an invention relative to its past (the future within the limits set by the discounting rate). With a large proportion of inventions made never reaching the development stage, the estimate of their gross economic contribution is purely a forecast; and that of their net contribution is

\footnotetext{
${ }^{1}$ It may be of interest to note that in estimating the returns from research and development expenditures the prevailing practices of firms follow rather rough and ready formulas, utilizing arbitrary percentages of sales or returns, arbitrary time periods over which to credit the invention or improvement with the effects, and perhaps no less arbitrary estimates of the probability of success (see, e.g., Science and Engineering in American Industry: Final Report on a 1953-54 Survey, National Science Foundation, 56-16, Washington, 1956, pp. 49-52).

${ }^{2}$ See the ingenious analysis for the cases of hybrid corn and related innovations in the paper by Zvi Griliches, "Research Costs and Social Returns: Hybrid Corn and Related Innovations," Journal of Political Economy, October 1958, pp. 419-431.
} 
a double forecast, involving as it must some approximation to development costs still to be sustained. Even for inventions that have been selected for application as innovations, the estimate of the gross economic contribution to society is, within the limits set by the discount rate, necessarily a projection that has to embody numerous assumptions concerning future effects on production and the future behavior of market responses.

Second, if the invention is applied, it is likely to become the vehicle of a host of obvious and minor improvements (perhaps more so in the early phases than in the later) whose cumulative impact in reducing costs will be large indeed. Should we credit the original invention with all these improvements (denying credit to the latter) when assessing its economic contribution? The question has even wider ramifications. An invention introduced into a given industrial operation may not only give rise to improvements in that operation, but may also stimulate greater productivity elsewhere. For example, the standardization of cotton thread attained by the mechanization of spinning permitted some minor improvements in weaving (even before its mechanization) which would not have been possible with handspun thread. Should we credit the improvement in weaving to the invention of a mechanical spinning device?

An unequivocal answer is not easy. Although many inventions do provide bases for a host of obvious and minor improvements which otherwise could not have been made, it does not seem defensible to credit an invention with savings realized at times and places often remote from the original invention and inventor. The defensible answer, difficult as it might be to apply in practice, would be that the acceleration in the rate of minor improvements-over and above the usual run of obvious improvements in production processes-should be credited to the invention; and if we distinguish primary inventions from auxiliary inventions connected with them, it may be more justifiable to measure the economic contribution of a whole complex of related inventions. In that case the economic contribution would be measured by additions to output attained by the whole complex, including the higher rate (higher compared with industries unaffected by the new complexes) of obvious and minor improvements. The difficulties we would encounter if we used such a definition of economic contribution need not be emphasized. And yet in any rational calculation of economic returns from an invention some estimate of the 
contribution of the accelerated rate of minor improvements should obviously be taken into account - minor improvements in the process or product itself, from the standpoint of the firm; and both these and an accelerated rate of minor improvements elsewhere from the standpoint of society as a whole.

Several conclusions which emerge from this all too sketchy discussion of the magnitude of an invention seem particularly relevant to the problem of measurement.

First, inventions differ widely with respect to the magnitude of technical problem overcome, technical potential, and economic contribution. Untested inventions may differ widely with respect to economic cost and tested inventions surely differ widely with respect to their development costs.

Second, the magnitude of technical problems overcome may be positively correlated with the technical potential of an invention and the latter with its economic contribution. We may, therefore, assume, although none too securely, a positive association between the magnitude of technical problems overcome and the economic contribution of an invention.

Third, there is no reason to assume significant association between the economic cost to the inventor of a single untested invention and its potential economic contribution. However, some relation can be assumed if we assign to a given invention, or a related group of them, the total cost, including that of unsuccessful attempts. For if a given area seems to a wide group of inventors to be potentially profitable, the costs devoted to that area would be larger than those expended elsewhere and if the judgment is correct, economic costs of inventions would be large in areas where their potential economic contribution is large. This, of course, assumes free market operation in the matching of costs and potential returns and disregarding the effects of government subsidies, etc. And if we include development costs, there is more reason to expect that the cost of tested inventions would be positively associated with the potential economic contribution, for presumably-again on the assumption of free operation of market forces-the greater resources needed for development would flow in directions that seem most promising from the standpoint of potential economic contribution-as judged by the criteria of the given firm, although not necessarily by the criteria of social usefulness. 


\section{Measures of Input}

The difficulties in the measurement of input are those involved in identifying the input and in evaluating it.

The major questions of identification may be stated as follows. Does the effective prosecution of inventive activity depend upon a certain relatively rare capacity of the human mind for which there is no possible substitute in the combined efforts of several less gifted individuals? Or is inventive ability widely distributed, even if at different levels, so that the body of potential inventors is limited only by the size of the adult population and the resources available for its education and by the time and facilities needed for effective inventing? Is there quantitative comparability in inventive capacity, i.e., can one man-hour of labor by a person at the $x$ level of ability be equated to $n$ hours by a person at the $y$ level of ability, and so on ?

If we assume wide variations in inventive ability and disregard for the moment the measurable resources involved in the educational and material facilities required for producing untested inventions, in order to measure the input in inventive activity - for the present in nonmonetary terms-we would have to: (1) spot individuals who, over a given period, engage in inventive activity; (2) ascertain the hours spent on such activity; and (3) weight these hours by some scale of inventive ability. Multiplying the hours by the appropriate weights we could then say that so many equivalent man-hours of inventive capacity have been "put-in" during the year.

The disparity between the data usually available and those suggested above can easily be gleaned from the literature. In his illuminating article, "Inventors, Past and Present,"3 Jacob Schmookler presents findings for a small sample of persons to whom patents were granted during four weeks in October and November 1953. These findings are assembled with cross-section correlations of state data on patents and number of "technologists" (treated as would-be inventors), and defined in two ways: the narrower definition includes electrical, mechanical, chemical, industrial, mining, and metallurgical engineers, plus chemists, assayers, and metallurgists; the wider group includes also civil engineers, architects, designers, draftsmen, the very minor group of inventors proper, and surveyors. From our standpoint two of the conclusions are of particular interest. First, even in recent years, "invention remains primarily a part-time activity. Somewhat

${ }^{3}$ Review of Economics and Statistics, August 1957, pp. 321-333. 
less than half of all inventions are made by full-time inventors, the rest being contributed by executives, line technologists, and individuals in a wide variety of other occupations working in their spare time"; second, "about half of inventions patented are still being made by individuals who lack college educations". ${ }^{4}$ Thus, even if we disregarded the question of the comparability of man-hours of individuals endowed with different inventive capacities, and assumed that all man-hours were equivalent (or allowed only for differences associated with education, which apparently are not the most important), we would still have no measure unless we could estimate the part-time total of a large number of potential inventors.

But the problem of comparability is crucial, since it affects the whole question of supply of inventors and inventive activity. The limits to the possible supply obviously depend upon whether or not we assume a wide spread of inventive ability and gradation among the successive levels that would permit some quantitative comparison. Any light that professional study of human capacities can shed on this question would obviously be valuable. Moreover, we need far more empirical study than we have had so far of the universe of inventors; any finding concerning inventors, identified in either uniform or diverse fashion, would be of great value-not only for the measurement of input but also for public policy in regard to inventive activity. For the present, the number of "technologists" can give us an inkling of the temporal or spatial differences in input of man-hours of equivalent inventive capacity only on the assumptions that: (1) the proportion of technologists engaged in inventive activity and the average hours each devotes to it are constant in time or equal in space; (2) the man-hours of nontechnologists are in constant proportion to the man-hours of technologists over time or the same in space; (3) either all man-hours are equivalent, or the average man-hour has the same capacity weight for both technologists and nontechnologists, and is constant over time or the same in space. Clearly, these assumptions are unrealistic, although one would be hard put to it to assess the degree of unrealism. Does the average man-hour of nontechnologists have a lower weight as an index of inventive capacity than that of technologists, and if so, how much lower, and how has the coefficient changed over time? Has there been a rise over time in the proportion of technologists engaged in inventive activity? We do not have the answers to these questions, and must guess at the qualifications that the acceptance of the above

Ibid., p. 329. 
assumptions impose on the use of the number of technologists as an index of physical volume of input of inventive activity.

Even if we could establish a scale and measure man-hours of inventive activity of equivalent capacity we would face the problem of valuation. How do we value these man-hours for comparison with other (material) resources employed in inventive activity and for comparison of the total with other inputs in the economy? Can we assume that compensation paid by the market to hired inventors (full-or parttime) or the revenue which the market secures to an independent inventor reflects a yardstick similar to that used for other resources in the economy? To be more specific, can we assume that the compensation of a hired inventor is determined by marginal productivity, with the flow of supply such that the marginal cost of an additional unit will not exceed or fall far short of the marginal return? Considering the difficulty of estimating the economic contribution of inventive activity suggested in the preceding discussion of the magnitude of an invention, the assumption of marginal productivity would surely strain one's credulity. On the one hand, one may argue that, in the aggregate, compensation to inventors, hired or independent, full-time or part-time, is well below any reasonable estimate of the assignable social product of their activity - partly because of the existence of nonpecuniary rewards, and largely because of the narrowness of the private market demand for many types of socially useful inventions. On the other hand, one may argue that, in some industries in which inventive activity is lavishly financed because of a general belief in a wide technical change potential, aggregate wages paid to employed inventors are too high (in comparison with other commodities and services) because of the inability of firms to distinguish between the fertile inventive mind and the educated hack. Since the market mechanism can so easily fail, one may wonder whether an increase in the real salaries of hired inventors actually means an increase in the input of inventive activity. It does represent an addition to the volume of resources devoted to sustain a particular group of people but it is no assurance of any rise in the input of inventive activity measured on some scale of inventive capacity.

This defect is inherent in the money measure of the input of any factor that cannot be effectively appraised by the market in terms of its quality or productivity. Obviously, it is a major deficiency of the available series on research and development expenditures by corporations, governments, and universities. Postponing for the moment 
consideration of other qualifications of the series, I would like to stress one implication of the argument above: that in dealing with the input of inventive activity an attempt must be made to go behind the money veil and to measure physical volume with allowance for quality differentials. True, such an approach would lead into the difficult field of inventive intelligence tests and personality studies and would, at best, yield a quantitative measure of inventive capacity not combinable with the dollar values of reproducible resources so much better evaluated by market prices. Such a measure would still be more useful than dollar value totals which reveal little about the productive factor involved. If, as is most likely, the supply of human talent is the bottleneck in inventive activity, and if we can derive acceptable measures of the input of this factor alone, we should eventually be able to study the effect of differences in its input, in combination with various amounts of material resources, on the output of inventions.

But to return to the series on research and development expenditures ( $R$ and $D$ ), they obviously suffer from limitations other than the inadequacy of the money yardstick in measuring the input of inventive capacity (the volume of inventive activity, as distinct from the volume of its output). To begin with, they exclude individual and independent inventors, whether full- or part-time; and in the light of Schmookler's study, the omission is substantial. Then, they include expenditures not only on applied research (which for practical purposes could be considered a fairly close approximation to inventive activity), but also on basic research (a small fraction of the reported total) and far more important, on development work. Development expenditures are probably far larger than expenditures on applied research proper, particularly among business corporations (whose outlays dominate the level and trend of $\mathrm{R}$ and $\mathrm{D}$ expenditures, including and excluding government financing). The line of distinction, although difficult to draw, is important: development expenditures begin when an invention, having been shown to "work," has been chosen for application (provided the technical problems of adjustment, prototypes, pilot operation, etc. permit extended operation, i.e., conversion of an invention into an innovation). Such expenditures are likely to be large because working out the patterns of operation, eliminating "bugs", and making successive trials and removing errors are all time consuming and require a great deal of material capital and skilled resources. I do not mean to disparage development work when I exclude it from inventive activity; it certainly makes demands upon ingenuity, tech- 
nical knowledge, and ability. But it is a job of adjustment within given patterns of the production process; it is not original invention. And particularly important, the basis of decisions and the human personnel involved in development work are quite different from those involved in inventive activity. In studying this whole area of human endeavor, we probably would benefit by keeping the two activities-inventions or applied research, and development work-apart although naturally both would have to be studied in covering the full range from scientific discovery to economic innovation and spread. ${ }^{5}$

On the basis of this distinction and the implied definition of inventive activity (used throughout this paper), expenditures on applied research or inventive activity are probably a limited fraction of total $\mathrm{R}$ and $\mathrm{D}$ outlays. The actual fraction is a matter for guesswork, but the available data on the high ratio of development invention costs in those areas (aircraft, electronics, and the like) in which $R$ and D expenditure totals loom large, suggest a fraction that does not exceed one-seventh. ${ }^{6}$ If it is inventive activity that we wish to study, then we should not dim our view of it by using measures that are incomplete or so inclusive that inventive activity expenditures are only a small and probably variable fraction of the total. ${ }^{\text {? }}$

\section{Measures of Output}

The problems in measuring output of inventive activity are similar to those in measuring input: the difficulties of identification and of valuation. But much more data, quantitative and qualitative, are available on output than on input. The monographic and periodical literature that records at least the important inventions in various industries is far richer than that bearing directly upon activities,

\footnotetext{
${ }^{5}$ The apparently opposite stand taken by Willis $\mathrm{H}$. Shapley on the need for distinguishing in the budgetary statistics between outlays on research and those on development stems, as I read it, from a view similar to that presented here, that money totals are a poor measure of input of inventive activity or of applied research ability (see his "Problems of Definition, Concept, and Interpretation of Research and Development Statistics," in Methodology of Statistics on Research and Development, National Science Foundation, 59-36, Washington, 1959, particularly pp. 12-13).

${ }^{6}$ After I made the guess cited in the text, an estimate was published by Dexter M. Keezer, Douglas Greenwald, and Robert P. Ulin, in their paper, "The Outlook for Expenditures on Research and Development during the Next Decade," American Economic Review, Papers and Proceedings, May 1960, pp. 355-369. The authors estimate the share of applied research in total $R$ and $D$ expenditures at between 22 and 22.5 per cent (see Table 3, p. 364).

${ }^{7}$ I do not mean to underestimate the difficulty of making the distinction in statistical collection. Nor are the observations above meant to minimize the high value of the new data in what is essentially a very difficult field.
} 
characteristics, and origins of inventors and other information on input. Moreover, we have long statistical series on patents for a number of countries as well as voluminous unpublished data in the files of the national patent offices. Hence, instead of beginning with a further specification of the difficulties of proper measurement of outputwhich is perhaps unnecessary after our earlier discussion-we can immediately consider the data available, and begin with the statistics on patents. ${ }^{8}$

Before noting some of the limitations of the patent series, it would be well to point out its advantages. A patent is presumably issued after a test has been made of an invention's technical soundness, i.e., whether it matches the inventor's claim, and, in most countries, after a search has revealed that a similar invention has not already been patented. We may therefore assume-allowing for the fallibility of any human process - that a patent represents a new and technically feasible device. Furthermore, since it takes time and money to secure a patent, its issuance is evidence that someone-either the inventor or his backers-believes that the potential economic value of the patent warrants the expenditure. To be sure the costs are not large and some patents are taken out for their nuisance or blackmail value but unless the proportion of such patents is large or variable, the qualification they impose upon the statistics of patents as a count of new, technically feasible devices with some potential economic value is limited.

Note that these and subsequent comments refer primarily to patents issued-not to patent applications. Although some time distortion is introduced by the varying efficiency of the patent office into the series of patents issued as compared with applications, it is the issuance of a patent that assures a test of soundness and newness. Even that may be upset by subsequent challenge and litigation, and perhaps the series of patents issued net of upsets is the most unequivocal index of new devices of potential economic value. But there is no need to dwell here on technical details and on the possibilities of using one series as an approximation to the other.

The impressive advantages of patent issues as a measure of output of inventive activity, are offset by disadvantages under the heads of both identification and valuation. First, not all inventions are patented.

${ }^{8}$ The best recent discussion of the patent data is that by Jacob Schmookler in an unpublished paper, "A Critique of Patent Statistics and a Review of the Literature." I have profited greatly from it, although I disagree at points with Schmookler's conclusions. 
Given the costs involved in securing a patent, the danger of competitive imitation resulting from the compulsory revelation of the new device, the cost of possible litigation in defending the patent, and the ability of an enterprise originating or possessing the new device to reap most of the benefit of pioneering without patent protection, the number of inventions that are not patented may be large. It has been suggested that the failure of the number of patents issued in this country to rise significantly since the 1920 's may be due to an increasing volume of inventions for which no patent is sought. This hypothesis gains some support from the increasing proportion of patents assigned to firms, which implies that a growing number of inventions are originating under conditions in which a patent is not indispensable (as it is to an independent inventor) to assure the economic benefits to be derived. A contributory factor may be that many inventions are originating with large firms (which have the dominant proportion of private research departments) who fear that securing of patents may expose them to accusations of violation of anti-trust regulations. Another factor may be the growing financing of private research by government. Also relevant may be the increasing extent to which scientific discovery in some fields facilitates the development of alternative devices, so that patenting the pioneering device is no protection against effective competition. Whatever the reasons, there probably are variations in the extent to which the series of patents issued covers all the new technically feasible and potentially profitable inventions. It is also likely that the patent system in this country has become increasingly deficient in coverage in recent decades.

But the main difficulty with patent statistics is, of course, the enormous range in the magnitude of the inventions covered. Obviously, we cannot assume that one patented invention is, in any meaningful economic sense, equivalent to another. It is in this economic sense, the potential economic contribution of an invention, that we are naturally interested. As already indicated, the potential economic contribution of an invention when it is completed but before it has been tested and applied on an adequate scale is a rather conjectural quantity, and it would be difficult to attach such an estimate to each patent. Yet patented inventions do differ widely in their potential economic magnitude: a patent for a new corkscrew or plow sulky cannot be equated with one for a new gas combustion engine (although the former may eventually be economically more profitable, privately and socially, than the latter). Even at present, with a restricted and selective use of 
the patent system and a greater proportion of patents assigned to firms, one-third to four-tenths of all patented inventions do not reach commercial use by the end of the fifth year after patent issuancea clear indication that for a substantial proportion of patents the implicit claim of economic usefulness is not confirmed. Furthermore, the range of economic contribution among patents that do find commercial use is very likely wide. To be sure, an ex post facto judgment of the economic potential of an invention in terms of its success in finding commercial use and of its contribution when used assumes that the economic contribution is properly determined by the play of market forces. It implicitly assumes that business firms are on the lookout for new inventions, appraise them tolerably well in terms of their potential, and then allocate resources to their development so that the maximum possible net contribution is realized. There may be flaws in this assumption since no human institution works that rationally, but I see no reasonable alternative to accepting it as a tolerable working rulewith the necessary qualifications for monopolistic action, human ignorance and folly, and for some inventions, the disparity between private and social return.

If individual patented inventions differ widely in economic magnitude, would the average for a large sample be constant over time or of approximately the same level across space? Would 1,000 patents, or the total for a given year (and they have been averaging 40,000 per year in this country in recent decades) have the same average economic value as the total twenty or fifty years ago; the same in New York state and in California; the same in this country and in the Netherlands? The answer cannot be given with assurance, but there are grounds for saying "no". The marked shift since 1900 in the distribution of patents from those assigned to individuals to those assigned to firms, the growing proportion of technologists among those securing patents, and the indication of a rise in the proportion of patents reaching commercial use all lead one to infer that there has been a secular rise in the average economic potential of a patent over the years, in this and perhaps in other countries. Other factors may have offset this trend, especially the nonpatenting of inventions directly exploitable by the originating firms, since it removes from the patent statistics one group of economically significant inventions. But the assumption that the raising and diminishing factors balanced each other in the long run, let alone in the short, is unwarranted; and the conclusion that the average economic magnitude per patent for any 
large group or the whole universe remained constant over time is unjustified. Indeed, the secular trends in the average values may have been quite marked. If so, it would be difficult to conceive that the averages are the same in different areas, industries, or other aggregates: each of these is a different compound of factors that produce trends over time, and it is unlikely that the balancing of these factors would produce equal average values. In short, one must conclude that the easily available statistics on the number of patented inventions are in units for which even the average economic value is variable-subject to significant trends over time and significant differences in space.

But this does not mean that the data are arbitrary and worthless. We need not assume that the trends over time and differences in space in the average economic values are so large as to overwhelm the indication that patent statistics may provide of the collective judgment of inventors and the resulting output differentials. To use an extreme illustration: if one patent is issued in area $\mathrm{A}$ and one thousand in area $B$, we could hardly conclude that the output of new inventions, measured by their potential economic contribution, is not larger in area $\mathrm{B}$ than in area $\mathrm{A}$. Inventors are not complete ignoramuses and their flocking to area $B$ would reflect a higher appraisal of economic potentialities there than in area $A$; and such flocking would include inventors with different capacities, up to the highest. Consequently, it would be dangerous to assume that the inventors in area $B$ are idiots whose output is outweighed by that lone genius in area $\mathrm{A}$. This reasoning may be completely wrong in any specific comparison, but it probably is valid in the overwhelming proportion of cases. In any event, it is presented here only as an example of the kind of assumption one must make concerning the responses and judgments of inventors as reflected in the patent statistics. The validity of the assumption used clearly depends on the characteristics of inventors, for it is they that determine the extent to which the collective judgment of inventors can be relied upon for an appraisal of the economic potential. If this collective judgment is not arbitrary but has some ascertainable relation to testable reality, it should be possible to interpret patent statistics as meaningful indexes of the output of inventive activity-despite the wide range in the economic contribution of individual patents or variations in the averages for large groups. The studies by the few scholars who have devoted attention to this material-Schmookler, Stafford, Sanders, and others-indicate that the data are neither arbitrary nor capricious, and that they can provide the basis for a 
great deal of insight into the distribution and even the volume of invention output. ${ }^{9}$

Three other comments can be made in this discussion of patent statistics. First, one can fairly say that even the easily available patent statistics have not been studied adequately. Despite the illuminating studies in this country by the scholars already mentioned and a handful of studies in other countries, I would conclude that the analysis has lagged far behind the accumulation of data. Of course, such a lag exists in practically every branch of empirical study of economic (and I suspect of all social) phenomena. The typical conjunction of the production of primary data by government and other agencies for administrative or general social intelligence purposes with the scarcity of scholarly analysts and of means at their disposal make a lag almost inevitable. Yet, while no precise measure of this lag is at hand, my impression is that it is much wider in the field under discussion, with specific reference to patent statistics, than in the study of many other production sectors in the economy. We are thus handicapped in attempting an appraisal of the possible yield of patent statistics because they have not been sufficiently analyzed.

Second, the mere number of patents, or even their classification by industry or process (and we have little of the latter) is only a fraction of the information in the files of the patent offices. At least in this country (I am not familiar with the situation in others), each patented device is described in some detail at the time of application and issuance. I am not a technologist and cannot fully appraise the value and potential uses of such information. But the latter is conceivably raw material for a more intensive study of the output of inventive activity than is possible on the basis of a mere count of patents or their summary grouping into several classes. And, of course, these additional data would permit identification of the patentors, and provide an initial step in the study of characteristics of inventors that is indispensable for a better analysis of the supply side of inventive activity.

Finally, one may fully admit that the patent data, summary or otherwise, are not a direct and efficient measure of the output of inventive activity, whatever analytically oriented definition of the latter we may agree upon. The relation is analogous to that between the primary

\footnotetext{
${ }^{9}$ It would seem to me that the data are better indexes of output than of input. Their defects as measures of output, i.e. of product of inventive activity, remain if they are considered as measures of input, since input must record differences in capacity for inventive activity. And they are a far more complete measure of output, since the input that failed to produce a patentable invention is not included.
} 
data and the processes or totals implied in the analytically oriented definitions of many other areas of economic activity. The raw body of statistics does not contain data on output of capital goods or even on a clearly defined industrial sector, but we have been able to translate it into some rough but meaningful approximation to the concepts needed for analysis. The links connecting the original data with the analytical concepts were found only by intensive attempts to use the data. Some of the unexpected revelations that such studies provide are of immense value in identifying these links or in revising the concepts to render them operational without fatal loss of their analytical clarity and usefulness. This is but an elaboration of the comment above on the lag of analysis behind accumulation of patent data; but it specifies the service that the reduction of the lag through further study can make toward increasing the value of the data as measures of output.

Related to and supporting this conclusion is the possibility of using monographic and periodical literature (trade and industry journals, files, etc.) for a study of inventions that have been applied and have proved sufficiently important to deserve notice by historians and analysts interested in the development of specific industries and productive processes. These records register only a small proportion of the thousands of patented inventions in any one industry: they omit the host of inventions which are minor either in the technical or economic sense. But they can yield a fairly acceptable list of inventions that have proved important, with the possibility of distinguishing some order of importance. Too few such attempts have been made to establish a fully defensible basis of selection. But if the latter represents an acceptable consensus of experts in the field, the resulting selection is extremely useful, both for comparison with the yield of a study of all patents in a given area and particularly as a basis for more intensive analysis of successful inventions.

\section{Concluding Comments}

The gist of the discussion in this paper may be reduced to three propositions.

1. Despite the overlapping among scientific research and discovery, inventive activity, and design and development work, the attempt to distinguish inventive activity would mean a sharper definition of focus 
and better research strategy. It would promise a more effective concentration of empirical data and analytical examination on the input of a distinctive ability, and on the output of a distinctive product. Of course, both the productivity of the input and the translation of the output into economic production depend upon and are affected by the other links in the chain from discovery to innovation. But granted that the study of inventive activity, like that of any process that is linked with others, can be useful only if there is a minimum parallel effort made on the other links in the chain, this does not mean that it is desirable to merge basic research, inventive activity, and development work into a fused mass and deal with the total input and output, without an attempt to differentiate among the three.

2. Proper measurement of the input in inventive activity requires some gauge of inventive capacity in addition to measures of reproducible resources, whether invested in education or in material capital. All these are needed, but the human ability resource is more crucial than the material capital and the money value of education. Money measures are of doubtful significance here. Disregarding the question whether this is a proper field for economists (it obviously is not), there is need, if relevant input measures are to be constructed, to draw upon the study of specialized human abilities.

3. No efficient measures of the output of inventive activity are available now. A variety of data-patent statistics, patent office files, selected lists of inventions in monographic and periodical literaturedoes exist but it has been barely utilized. According to preliminary indications provided by studies already made, it can with further work yield some quantitative indexes of the output of inventive activity - at least of rough trends and differences in the economic magnitude of new inventions in various fields at various times. The data are incomplete, since unpatented inventions escape attention; but they can yield far more information on trends and differences- to be linked with scientific discovery at one end and innovations at the otherthan has been secured so far.

Judgments such as these can hardly be offered as firm conclusions. Discussion of definitions, the purpose of which is to delimit a field of inquiry through specifying its distinctive and constituent characteristics, can lead to no more than judgments whose relevance can be tested only by the development of research in the field. Likewise, discussion of problems of measurement can, unless much quantitative work in the field has already been done, lead only to suggestions that 
still have to stand the test of prolonged experimentation with the linkages between the available data and the desired quantitative counterparts of analytically defined concepts. The field under consideration has not reached the state of development in which canons of definition and measurement can be derived as conclusions distilled from already accumulated experience. Under the circumstances, all the propositions above can be advanced only as subjects for critical examination and debate; but more usefully as threads in the search for guidelines for further substantive research in the field.

\section{COMMENT}

JACOB SCHMOOKLER, University of Minnesota

When the other papers are considered against the background of Simon Kuznets' contribution, it seems clear that in many respects the conference is concerned not only with inventive activity as Kuznets defines it but with other kinds of knowledge-producing activity as well. The full range of activities covered can be delineated as follows.

1. APPLIED SCIENTIFIC RESEARCH. This may be defined as a planned search for new knowledge which is expected to have a practical pay-off. This term is intended to cover both basic research in industry and applied research as defined by the National Science Foundation. The NSF defines applied research as "Research projects which represent investigations directed to discovery of new scientific knowledge and which have specific commercial objectives with respect to either products or processes."' It defines basic or fundamental research (in industry) as "Research projects which represent original investigation for the advancement of scientific knowledge and which do not have specific commercial objectives, although they may be in fields of present or potential interest to the reporting company." 2 The reason for here including basic research in industry in the category of applied research is simply that such research is ordinarily expected to have an industrial application, though its precise character is not foreseen. Otherwise, firms would be unlikely to spend money on it.

Note: The author wishes to express his indebtedness to $\mathrm{O}$. $\mathrm{H}$. Brownlee for his criticisms of an earlier version of these comments.

${ }^{1}$ Science and Engineering in American Industry: Report on a 1956 Survey, National Science Foundation 59-50, Washington, 1959, p. 95.

${ }^{2}$ Ibid. 
2. DEVELOPMENT. This may be defined as technical activity concerned with the nonroutine problems encountered in creating or improving industrial products or processes. ${ }^{3}$

In short, applied research is the search for new knowledge about natural or industrial products or processes with the expectation that the knowledge gained will be useful. Development is the effort expended in creating or improving industrial products or processes. The latter may or may not be based on knowledge gained in the former. As used here, applied research is concerned with the discovery, development, and creation of economically useful knowledge. The two activities combined represent the sum total of society's technology fostering efforts. "Pure research" stands apart from both, in that its primary purpose is the acquisition of knowledge for its own sake.

What is "inventive activity" and where does it fit in to this framework? We can define the term broadly and include all effort, from the initial exploratory work into the nature of phenomena carried on in the expectation that some use for the knowledge gained will result, to the formulation of the central properties of a new or improved product or process and the reduction of the idea to a form suitable for routine use in production. In that case, inventive activity is coextensive with applied research and development as defined above. Alternatively, we can so define it as to include only (a) the formulation of the central properties of the idea, and (b) its reduction to the point where it works, whether or not it works efficiently. The latter is essentially the definition which Kuznets proposes, and it corresponds substantially with the effort required to produce a patentable invention.

I shall use the second, Kuznetsian, definition on the ground that the character of such effort, certainly historically and probably currently as well, differs in many important ways, as Kuznets argues, from that involved in scientific discovery on the one hand or engineering development on the other. However, while Kuznets believes that inventive activity in this more restricted sense corresponds to that designated by the NSF as applied research, 1 gather from a conversation with

${ }^{3}$ The NSF defines development as "Technical activity concerned with nonroutine problems encountered in translating research findings or other general scientific knowledge into products or processes," Ibid. This definition unfortunately involves the unwarranted assumption that new or improved products invariably emerge from a prior scientific base. 
Jacob Perlman, Head of the Office of Special Studies, that the problem is not simple. According to Perlman, inventions in patentable form generally come from the development phase, while the central ideas come from applied research. In my opinio 7 , however, if the respondents to the NSF questionnaires follow the NSF definitions religiously, only activity expended on scientific discovery takes place in applied research and all invention takes place in development. Be that as it may, if research discovers what exists but was not known, while development creates what did not exist before, then invention is a phase of development. Separating research from invention is analytically useful, although in practice the two activities are often inseparable, so that the distinction is in one sense artificial.

Development as defined both here and by the NSF yields many minor and unpatentable improvements as well-improvements which I would call subinventions. Thus, the NSF definition of the activity includes "engineering activity required to advance the design of a product or a process to the point where it meets specific functional and economic requirements and can be turned over to manufacturing units. The design, construction, and testing of pre-production prototypes and models and 'engineering follow-through' in the early production phase is included. The development of designs for special manufacturing equipment and tools is included. ..." It therefore seems clear that while the problems dealt with in development are nonroutine, their solution often does not demand the creative faculty which the term invention implies. Whereas invention implies a result beyond that obvious to one skilled in the art, much development clearly does not.

To be sure, the degree of novelty required to constitute invention is open to dispute. To an outsider the paper bags, railroad rails, hayforks, etc., on which thousands of patents have been issued, might seem mere subinventions, and hardly inventions at all. Perhaps only those who have tried to make significant improvements in existing products or processes, or tried to produce nonroutine advances in any field of research, are likely to accept as proper the standard of novelty of the Patent Office.

Institutionally, invention is an activity engaged in by independent individuals, by corporations, and by governments. The objective is the improvement or creation of a specific product or process. The work requires examining the existing literature on the subject, theorizing,

- Ibid., p. 98. 
experimenting, formulating the essential properties of the new product or process, working it through to operational form so that subinvention can take over, washing out the test tubes, and sweeping up the floor.

Standing in a partially overlapping category are the applied research programs of ind ustry and the production-oriented, knowledge-creating activities of nonprofit institutions. These two, of course, might be classified in separate categories. They are joined here only because both are production oriented, and are distinguished from development in that, while they are intended to improve production, the resulting knowledge usually must be further "processed" before that objective is achieved. Applied research in industry and production-oriented nonprofit research typically aim at illuminating whole classes of natural or industrial phenomena, not a single, specific commercial product or process. Thus, the scientific discovery that diabetes can be controlled by injection of insulin extracted from the normal pancreas of animals had to be followed by the invention and other development of means of producing insulin industrially. Similarly, as Nelson points out in his paper, scientific discoveries in solid-state physics had to be followed by development before the new knowledge could be put to industrial use. By definition, applied research includes research in engineering, soil science, aerodynamics, pharmacology, medicine, etc., in nonprofit institutions. Moreover, even nonprofit work in basic science motivated primarily by the prospective economic or military utility of the result should likewise be included.

The relevant distinction is not between basic and applied, but between pure and applied research. The results of basic research presumably illuminate an aspect of nature, the understanding of which is fundamental to some branch of knowledge. When undertaken with this objective as primary, it may properly be called pure research. However, if, as with most contemporary viral or nuclear research, the sponsors (if not the researchers) pursue the research with potential economic or military uses uppermost in mind, it is applied, not pure, research. Moreover, not all pure research is or is expected to be basic. A census of butterflies in a region would be surely pure but not necessarily basic research, for example.

The distinction between invention, other development, and applied research on the one hand, and pure research on the other is important to make, at least if one is interested in the theory of economic development. Sometimes, more out of convenience than conviction, modern 
economists have treated the growth of knowledge as autonomous. Yet, only a modest understanding of the phenomenon is needed to show that this assumption is at least partly false. Just as our knowledge of mineral deposits under the surface of the earth has been built up largely because of the possibilities of economic exploitation, so too, much of our knowledge of science and technology has been developed with a similar objective in view. Hence, the distinction between pure research on the one hand and other. knowledge-producing activities on the other corresponds to the distinction which students of economic development draw between exogenous and endogenous variables, and pure research is a relevant exogenous variable to the degree that the resulting findings prove sooner or later to affect the direction and rate of economic growth.

The volume and location of these activities inevitably is influenced by the role of economic objectives and the product- or processspecificity of the expected results. Pure research, because of the absence of an applied objective, derives its support almost entirely from, and takes place entirely in, nonprofit institutions. By contrast, invention and other development take place almost entirely under the auspices of the presumptive principal immediate beneficiary, because the results take the form of specific products or processes, and are therefore in considerable measure appropriable directly by the sponsoring agent.

In contrast to development, the output of applied research, whether in the form of theories or data about natural or industrial processes and materials, is usually not product- or process-specific. This difference in specificity of results is associated with corresponding differences in their appropriability, which in turn helps explain the larger share of nonprofit institutions and trade association research organizations in the conduct of applied research.

Before we turn to a consideration of measurement problems, one final comment seems appropriate. The inherent uncertainty of each activity often takes the form of the attainment of unplanned results. In invention, a project designed to improve, say, automobile engines may yield as its major result a new metal alloy, an improved fuel, or a scientific discovery. Likewise, what was initially a project in basic science may produce instead a new invention, e.g. a cyclotron. The situation, again, is analogous to mineral exploration. Someone prospecting for gold may find iron or nothing; and vice versa, someone searching for iron or nothing may find gold. The discrepancy between 
ex ante and ex post is thus very great in knowledge-producing activities, and it is one that students of the growth of knowledge must bear in mind.

Let me turn next to the measurement of output. I shall confine my remarks to the economic value. When we assign an economic value to an invention, it is its value after (not before) full development that is involved. I shall therefore treat invention and other development as one for the purpose of discussion. In short, I am discussing the value of the invention in the form in which it is actually used or produced by industry.

As Kuznets and Machlup have shown in principle, and Griliches in practice, we can estimate the social value of an invention. Moreover, if we wished we could estimate what its value would have been if different conditions prevailed. Of course, for some purposes (e.g., a comparison of two inventions far apart in time or space), it is not its absolute value which is relevant but its percentage effect on output, cost, or per capita income. If we can estimate the value of a single invention, I think we can, in principle at least, do likewise for a whole stream. The practical difficulties, however, are another story.

By contrast, there may be a theoretical reason why we could not ordinarily estimate the value of any other kind of knowledge and this reason applies, incidentally, to any comparable effort to assign a value to what Kuznets calls "the technical potential" of a given invention. The economic value of other kinds of knowledge derives, so far as I can tell, entirely from their contribution to specific inventions. The reason we may be unable to estimate the value of knowledge other than inventions is that each item of knowledge is by definition unique. Now, inventions are largely new combinations of existing knowledge. Hence, in many if not most cases, an item of knowledge entering into the making of an invention is indispensable to its creation. Without it, the specific invention would be impossible.

With each ingredient of an invention unique, it may be as impossible to assign a specific value to a single item within the particular complex of knowledge constituting the invention, as it is to assign a specific value to the wing of an airplane in flight. We could say that the value of the single item of knowledge in this particular combination does not exceed the value of the invention itself, but this is a different and not very useful thing.

One implication of this, which has long been recognized and in a sense eloquently pointed out by Ogburn and Gilfillan, is that the value 
of a given invention reflects not only the resources expended directly in its production but also the resources expended in producing the prior knowledge on which it is based. Hence, just as many American inventions rest on basic European discoveries and inventions, so it is possible that the intellectual effort of a given period may deserve far more credit than its direct output of inventions would suggest.

Now, despite the fact that we cannot place a value on individual items of knowledge other than inventions, it would still be very useful to study the frequency with which particular inventions or other pieces of knowledge reappear in a different guise in the course of technological progress. Kuznets is quite right in emphasizing the different technical potentials, the varying seminal quality, of different inventions. I am only emphasizing that other knowledge possesses an identical quality, and that while this quality merits study, it will elude measurement.

On the other hand, a private firm would certainly want to estimate the value to it of the new knowledge it generates. In this case, the appropriate thing for it to do is, presumably, to estimate the value to it of the inventions it makes, and assign this sum either to its $R$ and $D$ program as a whole, or to those phases of the program which fed the particular inventions. It might conceivably even form some crude estimate of the value of the inventions yet to come from the research the company has already performed. The limited time span and the narrow confines of the operation make these more sensible undertakings for a firm than for society. It is all the more reasonable for the firm, since it does not have to assign any value to the knowledge it uses from the public domain.

Let me turn now to a few brief remarks about the measurement of input. Kuznets is, of course, entirely right in emphasizing the desirability of nonmonetary measures here. What one would like would be estimates of the physical and human inputs used, each in some relevant, homogeneous unit. From such estimates one might want to construct estimates of the invention production function.

Unfortunately, unlike other production functions (except those for other knowledge-producing activities, such as market research or mineral exploration), every act of production here may change the production function itself. All production functions assume a given state of knowledge. The purpose of the inputs in this case, however, is to change the state of knowledge. Hence, successive acts of production 
may occur under unique production functions. Moreover, different projects at the same time operate under different production functions for a similar reason.

But even if we are interested only in the inputs independently of the production function, we still have the problem of the heterogeneity of inputs conventionally called by the same name. The occupations involved in invention and research are far more heterogeneous than are occupations in most fields. It is a tolerable approximation to regard one unskilled laborer as the equivalent of another, but it is hardly tolerable to view engineers or scientists in this fashion. And the median chemical engineer of 1950 is hardly comparable with the median chemical engineer of 1900. Perhaps most important of all, men differ vastly in terms of their creative talent, their possession and use of the "inventive faculty." While I would like to see, with as much refinement as possible, data on physical and human inputs, we may have to settle for careful estimates of expenditure on inputs. Such estimates at least indicate the share of national product devoted to increasing technical knowledge.

This problem of the heterogeneity of input probably reaches its most acute form, as indicated above, in the case of the inventive faculty itself. What we would like, while we are writing out our Christmas list, is a measure of this faculty in psychological terms, since the phenomenon involved is essentially psychological. I would assume that psychologists can or will ultimately be able to isolate the inventive faculty in its various forms, and that they can or will be able to rank those who possess any particular form of the faculty according to the degree to which they have it. Such information would be of great value to educators, employers, and-if it were available for large groups or over extended periods of time for representative samples-to students of economic growth.

On the other hand, such data will be of more limited use than one would like. For example, we would have difficulty inferring from the inventive faculty of an individual as shown by a test score how much of that faculty he exercised in making a given invention, since the use of a capacity may be less than the capacity itself.

What is worse, I do not think, from my limited reading on the subject, that we could rank all the inventors operating in a given period according to their inventiveness, because different fields of invention appear to demand different kinds of psychological abilities as well as 
different kinds of training. ${ }^{5}$ The result is that $\mathrm{Mr}$. X can make invention A but not invention B, while Mr. Y can make invention B but not invention $\mathrm{A}$.

Worst of all, even if none of these problems existed, I do not believe that we could add together the psychological inventiveness test scores of the different inventors of a period and get a meaningful total-for the same reason that four men each with an I.Q. of 75 are not, in combination, twice as intelligent as one man with an I.Q. of 150. The differences among them are ordinal, not cardinal.

I am therefore forced to the reluctant conclusion that our interest in the distribution of the inventive faculty can be served only by studies like MacKinnon's of the psychological attributes of actual and potential inventors, and by studies of the factors which affect their development and functioning.

Let me summarize what I have tried to say. The conference is concerned with knowledge-producing activities of different kinds. Four broad categories may be distinguished : applied research, development, invention which is part of development, and pure research. Each of these provides knowledge inputs for the others and for itself. The differences among them run in terms of closeness to economic use, economic versus noneconomic motivation, and the degree of novelty (invention versus other development). The institutional differences and the extent of support accorded each activity largely reflect the differing appropriability of the results.

In principle and in practice we can and should try to get the best measures we can of the physical, human, and money cost of research and invention. We can likewise try to estimate the social returns from specific inventions. On the other hand, while we can study the inventive faculty in various ways with valuable results, one of those results will not be, in my judgment, an aggregate index of inventiveness, potentially or actually used, either for an industry or for the economy. Similarly, I do not see how we could assess the social value of that portion of knowledge which takes forms other than specific inventions.

${ }^{B} \mathrm{Cf} . \mathrm{H}$. Stafford Hatfield, who argues that the psychological attributes needed for successful invention are different in inorganic chemistry from those demanded in organic chemistry. Hatfield, The Inventor and His World, New York, Penguin Books, 1948, p. 131. 
